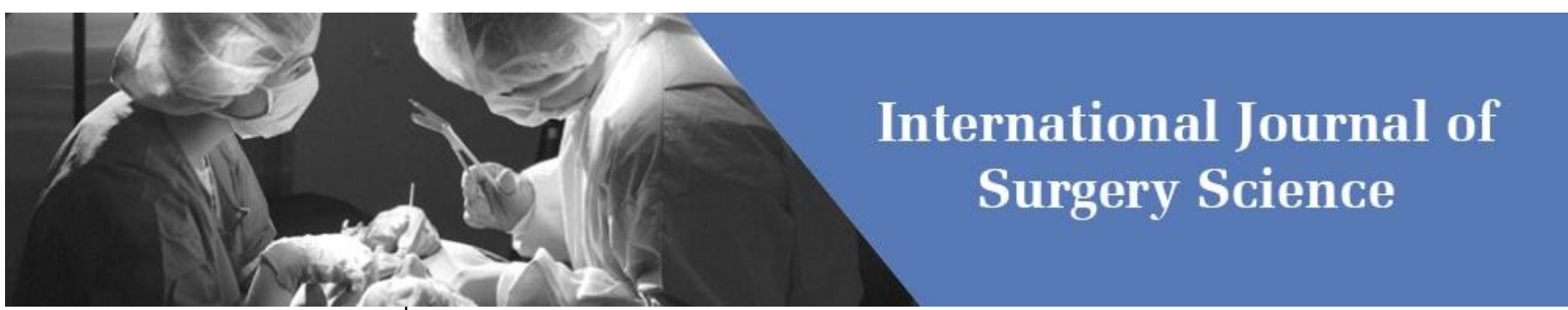

E-ISSN: 2616-3470

P-ISSN: 2616-3462

(C) Surgery Science

www.surgeryscience.com

$2020 ; 4(4): 24-27$

Received: 27-08-2020

Accepted: 02-10-2020

Pradeep Tenginkai

Senior Resident, Department of

General Surgery, KIMS, Koppal,

Karnataka, India

Santosh Nayak K

Assistant Professor, Department of

General Surgery, Karwar institute

of Medical Sciences Karwar,

Karnataka, India

Parthiban Nagaraj

Assistant Professor, Department of General Surgery, Aarupadai Veedu Medical College Puducherry, India

Corresponding Author:

Santosh Nayak K

Assistant Professor, Department of

General Surgery, Karwar institute

of Medical Sciences Karwar,

Karnataka, India

\section{Etiological factors, various modes of clinical presentation of acute intestinal obstruction}

\author{
Pradeep Tenginkai, Santosh Nayak K and Parthiban Nagaraj
}

DOI: https://doi.org/10.33545/surgery.2020.v4.i4a.533

\section{Abstract}

Background: Intestinal obstruction continues to be a frequent emergency, which surgeons have to face (1$4 \%$ of emergency operations). Intestinal obstruction is defined as any hindrance to the passage of intestinal contents.

Objective: To study the etiological factors, various modes of clinical presentation of intestinal obstruction. Setting: Study was conducted by selection of consecutive 50 cases presenting with symptoms and signs suggestive of acute intestinal obstruction from Chigateri General Hospital and Bapuji Hospital attached to J.J.M.Medical College, Davangere during the period from June 2009 to May 2011.

Result: the maximum incidence is in the age group of 41-50yrs. The occurrence of acute intestinal obstruction was common in male compared to female. Small bowel obstruction is more common. The commonest presenting symptom was abdominal pain followed by vomiting, distention of abdomen and absolute constipation. Adhesive obstruction (56\%) was the commonest cause of acute intestinal obstruction, followed by Obstructed Hernia (18\%), Malignancy (6\%), Volvulus (4\%), Intussusceptions $(6 \%)$ and TB stricture $(6 \%)$.

Conclusion: It was concluded that most common etiological factor for intestinal obstruction was postoperative adhesions. Obstructed Inguinal Hernia was the second most common cause of intestinal obstruction.

Keywords: Intestinal obstruction, intussusceptions, malignancy, hernia, volvulus

\section{Introduction}

Intestinal obstruction remains one of the most common intra-abdominal problems faced by general surgeons in their practice. This obstruction can involve only the small intestine (small bowel obstruction), the large intestine (large bowel obstruction) or via systemic alterations, involving both the small and large intestine (generalized ileus). Its early recognition and aggressive treatment in patients of all ages, including neonates, can prevent irreversible ischemia and transmural necrosis, thereby decreasing mortality and long-term morbidity. Ultimate clinical decisions regarding the management of these patients dictate a thorough history and workup and a heightened awareness of potential complications ${ }^{[1]}$.

Bowel obstruction remains one of the most common intra-abdominal problems faced by general surgeons in their practice. Whether caused by adhesions, hernia and neoplasm or related to biochemical disturbances, intestinal obstruction of either small or large bowel continues to be a major cause of morbidity and mortality. Its early recognition and aggressive treatment in patients of all ages including neonates can prevent irreversible ischemia and transmural necrosis, thereby decreasing mortality and long term morbidity. Despite many recent advances in our diagnostic and therapeutic armamentarium, intestinal obstruction will continue to occur ${ }^{[1]}$.

Mortality and morbidity are dependent on early recognition and correct diagnosis of obstruction. If untreated, strangulated obstruction causes death in $100 \%$ of patients. If surgery is performed within 36 hours, the mortality decreases to $8 \%$. The mortality rate is $25 \%$ if surgery is postponed beyond 36 hours in these patients. Patients with a bowel obstruction still represent some of the most difficult and vexing problems that surgeons face with regard to the correct diagnosis, the optimal timing of therapy and the appropriate treatment. Ultimate clinical decisions regarding the management of these patients dictate a thorough history and workup and a heightened awareness of potential complications ${ }^{[2]}$.

The purpose of this study was to find out the frequency of the conditions leading to acute small bowel and large bowel obstruction in the given setting. 
This will highlight the commonest causes of intestinal obstruction in the geographical location of the study which will suggest measures for prevention and treatment of the condition. Hence the present study was undertaken to study the etiological factors, various modes of clinical presentation of intestinal obstruction.

\section{Materials \& Methods}

The prospective study was conducted by selection of consecutive 50 cases presenting with symptoms and signs suggestive of acute intestinal obstruction from Chigateri General Hospital and Bapuji Hospital attached to J.J.M.MEDICAL COLLEGE, Davangere during the period from June 2009 to May 2011.

A clinical study of acute intestinal obstruction was selected because in routine practice every surgeon has to come across this surgical emergency and treatment would largely depend on early diagnosis and skilful management.

The prospective study was undertaken with the aim of evaluating the etiology, mode of presentation, clinical features \& management. A minimum of 50 consecutive cases presenting with acute intestinal obstruction in Bapuji Hospital and Chigateri general hospital was selected for the study. This is a prospective study of 50 cases presenting with symptoms and signs suggestive of acute intestinal obstruction.

A detailed structured Proforma was used to collect this information. All data was entered on master chart for analysis.

Inclusion criteria: Patients admitted with history of pain in abdomen, abdominal distention, vomiting and constipation with X-Ray and USG abdomen showing evidence of intestinal obstruction.

\section{Exclusion criteria}

1. All cases of sub acute intestinal obstruction.

2. Patient with acute intestinal obstruction who are unfit for general anesthesia.

All patients are subjected to required preoperative biochemical investigations. Plain X-ray erect abdomen was carried out in almost all patients except in obstructed inguinal hernias. Ultrasonography of abdomen was done in some cases whose diagnosis by X-ray was inconclusive. Patients who showed reduction in abdominal distention and improvement in general condition especially in individuals with postoperative adhesions, a chance of conservative management was taken (by extending the supportive treatment) for further 12 to 24 hours; those who showed improvement by moving bowels, reduction in pain \& tenderness was decided for conservative treatment, such individuals were excluded in this study. Patients with clear-cut signs and symptoms of acute obstruction were managed by appropriate surgical procedure after resuscitation. The nature of obstruction and the cause of obstruction were noted at laparotomy. A detailed structured Proforma was used to collect this information. All data was entered on master chart for analysis.

Result: Clinical study of 50 cases of intestinal obstruction was done at JJM Medical College, Davangere from June 2009 to May2011. The study showed incidence in all age groups ranging from newborn to $85 y$ rs. In our series, the maximum incidence is in the age group of 41-50yrs. Table 1
Table 1: Age distribution

\begin{tabular}{|c|c|c|}
\hline Age in years & Total cases & Percentage \\
\hline$\leq 10$ & 7 & 14 \\
\hline $11-20$ & 4 & 8 \\
\hline $21-30$ & 9 & 18 \\
\hline $31-40$ & 8 & 16 \\
\hline $41-50$ & 11 & 22 \\
\hline $51-60$ & 7 & 14 \\
\hline$>60$ & 4 & 8 \\
\hline
\end{tabular}

The occurrence of acute intestinal obstruction was common in male $(64 \%)$ with comparison to female $(36 \%)$ with male to female ratio $1.78: 1(2: 1)$. Table 2

Table 2: Sex distribution

\begin{tabular}{|c|c|c|}
\hline Sex & Number of cases & Percentage \\
\hline Male & 32 & 64 \\
\hline Female & 18 & 36 \\
\hline
\end{tabular}

There were more cases of small bowel obstruction $84 \%(42)$ when compared to large bowel obstruction $16 \%$ (8). Table 3

Table 3: Level of obstruction

\begin{tabular}{|c|c|c|}
\hline Level of obstruction & Number of cases & Percentage \\
\hline Small bowel & 42 & 84 \\
\hline Large bowel & 8 & 16 \\
\hline
\end{tabular}

The commonest presenting symptom was abdominal pain (100\%) followed by vomiting (92\%), distension of abdomen $(84 \%)$ and absolute constipation $(60 \%)$. Table 4

Table 4: Presenting symptoms

\begin{tabular}{|c|c|c|}
\hline Symptoms & Number of patients $(\mathbf{n}=50)$ & Percentage \\
\hline Pain abdomen & 50 & 100 \\
\hline Vomiting & 46 & 92 \\
\hline Distention of abdomen & 42 & 84 \\
\hline Obstipation & 30 & 60 \\
\hline
\end{tabular}

In this study, Adhesive obstruction (56\%) was the commonest cause of acute intestinal obstruction, followed by Obstructed Hernia (18\%), Malignancy (6\%), Volvulus(4\%), Intussusceptions (6\%), TB stricture (6\%), Mesenteric ischemia $(2 \%)$ and Nonspecific inflammatory stricture $(2 \%)$. Table 5

Table 5: Etiology of intestinal obstruction

\begin{tabular}{|c|c|c|}
\hline Etiology of Intestinal Obstruction & $\begin{array}{c}\text { Number of patients } \\
(\mathbf{n = 5 0 )}\end{array}$ & Percentage \\
\hline A. Adhesion and bands & 28 & 56 \\
\hline B. Hernia & 9 & 18 \\
\hline C. Malignancy & 3 & 6 \\
\hline D. Volvulus & 2 & 4 \\
\hline E. T.B stricture & 3 & 6 \\
\hline F. Intussusceptions & 3 & 6 \\
\hline G. Mesenteric Ischemia & 1 & 2 \\
\hline H. Nonspecific Stricture & 1 & 2 \\
\hline
\end{tabular}

Discussion: In the present series small bowel obstruction contributed to $84 \%$ and large bowel obstruction $16 \%$. This is comparable with reports of Michel ${ }^{[3]}$ and Becker ${ }^{[4]}$ where small bowel obstruction constituted to $80 \%$ and large bowel obstruction constituted $20 \%$. Since the advancement in 
understanding the anatomy/ physiology, fluid and electrolyte management along with modern antibiotics and intensive care unit; the mortality has been decreasing consistently. The associated medical problems (like respiratory cardiac or metabolic diseases) and advanced age carries a considerable contribution in adding the mortality.

\section{Age incidence}

Though intestinal obstruction occurs in all age groups, here the youngest patient was 9 months and oldest patient was 85 years. In this study $70 \%$ belongs to 21-60 years age group, previous study by Shakeeb, who noticed age distribution from birth to 85 years with an average of 50.7 years. A study by Gill Eggleston
${ }^{[5]}$ has reported $17 \%$ of cases in the age group of 50-54 years and $60 \%$ of the cases of intestinal obstruction occur in the age group of 30-60 years. These studies almost correlate with the present study.

However, a study reported by Harban Singh [6] and C. S. Ramachandran [7] says that the maximum number of cases occurs in the age group of 21-40 years, of these the etiological factors were obstructed hernia. The explanation which I would like to give in presently the etiological shift is towards adhesions and malignancy, which are more common in middle age and elderly population and also due to awareness; people are seeking treatment easily for hernia which is contributed to decrease in hernia related obstruction.

Table 6: Age wise incidence of intestinal obstruction in different studies

\begin{tabular}{|c|c|c|c|c|}
\hline Age group & Harban Singh $^{[6]}$ & Playforth $^{[8]}$ & S. S. Gill $^{[5]}$ & Present Study $^{[1-20}$ \\
\hline $10 \%$ & $4 \%$ & $12 \%$ & $8 \%$ \\
\hline $21-30$ & $16 \%$ & $5 \%$ & $12 \%$ & $18 \%$ \\
\hline $31-40$ & $18 \%$ & $13 \%$ & $13 \%$ & $16 \%$ \\
\hline $51-50$ & $15 \%$ & $18 \%$ & $13 \%$ & $22 \%$ \\
\hline$>60$ & $10 \%$ & $14 \%$ & $16 \%$ & $14 \%$ \\
\hline
\end{tabular}

\section{Sex incidence}

In present study, there are 32 male and 18 females. Male and female are in 1.78: 1 ratio. The male preponderance is consistent with series reported from other part of the world. Fuzan ${ }^{[9]}$ and Lee $^{[10]}$ reported 2:1 male to female ratio. Budharaja ${ }^{[11]}$ study a ratio of $4: 1$ between male and female.

\section{Etiology}

The most common etiological factor in the present study is adhesion which included postoperative, nonspecific and congenital bands. In the present series $56 \%$ of the cases of obstruction were due to adhesion and bands, $46 \%$ were due to post operative adhesions, $10 \%$ congenital bands. Perry et al, found that $79 \%$ were post operative adhesions, $18 \%$ inflammatory and $28 \%$ were congenital.

The etiology of intestinal obstruction varies from one country to other and from one part of the country to another party. The comparative study of previous report is as follows:

Table 7: Etiology incidence of intestinal obstruction in different studies

\begin{tabular}{|c|c|c|c|c|c|}
\hline Cause & Present Study & S.S. Gill and Egglestion ${ }^{[5]} \mathbf{1 9 6 5}$ & Playforth $^{\left[{ }^{8]}\right.} \mathbf{1 9 7 0}$ & C.S. Ramachandran $^{[7]}$ 1982 & Biarj et al. $^{[13]}$ 1999 \\
\hline Adhesions & $56 \%$ & $15 \%$ & $54 \%$ & $23 \%$ & $53 \%$ \\
\hline Hernia & $18 \%$ & $27 \%$ & $23 \%$ & $13.6 \%$ & $26 \%$ \\
\hline Volvulus & $4 \%$ & $25 \%$ & $3 \%$ & $26.6 \%$ & $3 \%$ \\
\hline Tuberculosis & $6 \%$ & $3.5 \%$ & - & $8.6 \%$ & - \\
\hline Malignancy & $6 \%$ & $3.4 \%$ & $9 \%$ & $9.3 \%$ & - \\
\hline Intussusception & $6 \%$ & $12 \%$ & $4.5 \%$ & $7.4 \%$ & - \\
\hline
\end{tabular}

On review of the earlier Indian studies $10 \%$ of intestinal obstruction were related to adhesion and more recent studies in 1982 reports $23 \%$. The rise in the incidence of adhesions related obstructions are attributed to increased number of abdominopelvic surgeries. In the Western studies the adhesion related obstruction range from 40-60\%. Developing countries like Virginia also reported $40 \%$ of the obstructions related to adhesions.

\section{Hernia}

In the present series 9 cases of obstruction are related to hernia $(18 \%)$ of cases. 5 cases of obstructed inguinal hernia and one case of strangulated inguinal hernia. one case of strangulated incisional hernia (female) and one case of strangulated - left femoral hernia (female). The comparative analysis of incidence of various studies reported the incidence from $13-35 \%$.

\section{Tuberculosis}

Tuberculosis is one of the common health problems in developing countries. In the present series, tuberculosis found to be a causative factor in 3 cases $(6 \%)$ in the form of ilio-caecal tuberculosis with stricture and adhesions.

Table 8: Tuberculosis percentagein various studies

\begin{tabular}{|c|c|}
\hline Harbans et al. ${ }^{[6]} 1971$ & $17.2 \%$ \\
\hline C.S.Ramachandran ${ }^{[7]} 1982$ & $8.6 \%$ \\
\hline Present study 2011 & $6 \%$ \\
\hline
\end{tabular}

Our present study corresponds close with the other Indian studies by C.S.Ramachandran ${ }^{[7]}$. However, disparity with western literature is due to the increase in number of tuberculosis patients in the rural population.

\section{Malignancy}

In the present study 3 cases $(6 \%)$ presented with acute large bowel obstruction. One case was Hepatic flexure growth, one at Sigmoid colon malignancy and one at the Recto-sigmoid junction.

All the 3 cases had annular types of growths occluding lumen totally. The incidence is higher in western countries due to various factors, which includes increased aged population, consumption of high animal fat and lack of fibre diet. 


\section{Volvulus}

Colon Volvulus is the common cause of large bowel obstruction of this sigmoid colon is involved commonly. In our study we had two case of Sigmoid Volvulus. Total percentage of Volvulus in our study is $4 \%$. The etiology may be primary where cause is not known and secondary due to adhesions, bands. This corresponds to the study done by Iwuagwu et al. ${ }^{[14]} 1999$, who reported incidence of $3.5 \%$ to $6.2 \%$.

\section{Intussuception}

In our study intussusceptions contributes about 3 cases $(6 \%)$ of obstruction. Intussuception is generally regarded as a disease almost exclusively of infants and is rare seen in adults. Gill et al in 1964 and Chatterjee et al in 1971 reported an incidence of $12.2 \%$ and $6.3 \%$. This corresponds to our present study.

\section{Clinical symptoms}

In our study, the commonest presenting symptom was abdominal pain (100\%) followed by vomiting (92\%), distension of abdomen (84\%) and absolute constipation (60\%).

Table 9: Comparison of presenting symptoms with different studies

\begin{tabular}{|c|c|c|c|c|}
\hline & $\begin{array}{c}\text { Pain } \\
\text { abdomen }\end{array}$ & Vomiting Distension & $\begin{array}{c}\text { Absolute } \\
\text { Constipation }\end{array}$ \\
\hline Present study & $100 \%$ & $92 \%$ & $84 \%$ & $60 \%$ \\
\hline $\begin{array}{c}\text { Budharaja } \text { et al. }{ }^{[11]} \\
(1976)\end{array}$ & $95 \%$ & $75 \%$ & $50 \%$ & $82 \%$ \\
\hline K.P,Rao et al. (1982) & $90 \%$ & $78 \%$ & $72 \%$ & $22 \%$ \\
\hline E.S. Palwe (1988) & $100 \%$ & $100 \%$ & $76 \%$ & $92 \%$ \\
\hline
\end{tabular}

Conclusion: It was concluded that most common etiological factor for intestinal obstruction was postoperative adhesions. Obstructed Inguinal Hernia was the second most common cause of intestinal obstruction. Malignant obstruction was far more common in large bowl, than in small bowl. In large bowel, malignant obstruction was more common on the left side than the right side.

Acknowledgement: I would like to express my profound gratitude to all the participants for their co-operation and for their immense faith they reposed in me.

\section{References}

1. Houghton SG, Medina AR, Sarr MG. Bowel obstruction. In: Zinner MJ, Ashley SW, editors. Maingot's Abdominal Operations. 11th ed. New York: Mc Graw Hiil companies 2007,479-508.

2. Mark Evers B. Small Intestine. In: Townsend, Beauchamp, Evers, Mattox, editors. Sabiston Textbook of Surgery. 18th ed. Saunders, an imprint of Elsevier 2008,1278-1332.

3. Michel ML Jr, Knapp L. Davidson A. Acute intestinal Obstruction; Comparative studies of small intestinal and colic obstruction. Surg 1950;28:90-110.

4. Becker WF. Acute obstruction of colon - An analysis of 205 cases. Surg. Gynaec.Obsetet1953;96:677-682.

5. Gill SS, Eggleston FC. Acute intestinal Obstruction. Arch Surg 1965;91:389-92.

6. Harban Singh et al. Acute intestinal obstruction: A review of 504 cases. JIMA1973;60(12):455-460.

7. Ramachandran CS. Acute intestinal obstruction: 15 years experience. IJS 1982,672-679.

8. Playforth RH et al. Mechanical small bowel obstruction and plea for the earlier surgical intervention. Ann Surg 1970;171:783-788.
9. Fuzan M, Kaymake E, Harmancioglu O, Astarcioglu K. Principal causes of mechanical bowel obstruction in surgically treated adults in Western Turkey. BJS 1991;78:202-03.

10. Lee SH, Ong ETL. Changing pattern of intestinal obstruction in Malayasia - a review of 100 consecutive cases. BJS 1991;78:181-182.

11. Budharaja et al. Acute intestinal obstruction in Pondicherry. IJS 1976;38(3):111.

12. Perry JF et al. Intestinal obstruction caused by adhesions. Review of 388 cases. Ann Surg 1955;142:810-816.

13. Biarj Tiddle et al. Complications and death after surgical treatment of small bowel obstruction. Ann Surg 1999;231(4):297-306.

14. Iwvagwu O, Deans GT. Small bowel volvulus. J Coll Surg EDINS 1999;44:150-55. 